\title{
Insights in the Postgenomic Era of the Folates, Vitamin B-12, Selenium and Public Policy in Health
}

\author{
Perla M Madrigal-Ruiz ${ }^{1}$, Sergio A Ramirez-Garcia ${ }^{2 *}$, Jareth M Cruz-Bastida ${ }^{3}$, Carlos E Cabrera-Pivaral ${ }^{3}$ \\ ${ }^{1}$ Department of Molecular and Genomic University Center for Health Sciences Biology, Meritorious University of Guadalajara, Jalisco, Mexico \\ ${ }^{2}$ Research Centre for Nutrition and Food, University of the Southern Highlands, State University System of Oaxaca (SUNEO), Mexico \\ ${ }^{3}$ Research Center for Social Development, University Center for Health Sciences, Meritorious University of Guadalajara, Jalisco, Mexico
}

*Corresponding Author: Sergio Alberto Ramirez Garcia, 2Research Centre for Nutrition and Food, University of the Southern Highlands, State University System of Oaxaca (SUNEO), Mexico, Tel: 01-376-7652325; E-mail: sergio7genetica@hotmail.com

Rec date: Oct 16, 2014; Acc date: Nov 24, 2014; Pub date: Nov 30, 2014

Copyright: (C) 2014 Ruiz PMM, et al. This is an open-access article distributed under the terms of the Creative Commons Attribution License, which permits unrestricted use, distribution, and reproduction in any medium, provided the original author and source are credited.

\begin{abstract}
In this perspective we present the advances in the study of the metabolism of folate, B-12 vitamin and selenium, whose deficiency is closely linked to the metabolic bone disease. However, the genetic variations of both mutation and polymorphism in genes are related to the metabolism of these nutrients and also lead to the development of monogenic and complex diseases. The challenge in the post-genomic era is to establish the genetic profiles related to megalin and selenoproteins in relation to serum levels of these vitamins in order to be analyzed as factors for the prediction and response to treatment of associated diseases. Governments should specifically consider the investment in this area, since the consumption of these vitamin and minerals are very common in food supplements.
\end{abstract}

Keywords: Vitamin B-12; Folates; Megalin; Selenoprotein

\section{Commentary}

One of the paradigms of medicine and public policy at the first level of health care in the post-genomic era is aimed at preventive medicine, the prediction of disease in subjects with risk factors and the long-term complications, and the realization of personalized medical practice, related to genetic profiles. The aim reduces costs in health care for patients, and their families, and to the medical units that provide care. This time we will only comment on the topic of interest that are closely related, and advances in the genetics metabolism of folic acid, vitamin B-12 and selenium. In the first level of health care it is very common that pregnant women are given folic acid to prevent neural tube defects and congenital heart disease, and are also prescribed with vitamin B-12 for palliation in the treatment of degenerative joint disease. Indeed these two measures have been useful in the prevention and treatment, and demonstrate the physiological relevance of these water-soluble vitamins. We must mention that the body depends on a specialized transport system primarily for its intestinal absorption and reuptake the proximal tubule of the nephron. This system is headed by megalin, the mechanism that is done through an endocytosis process. Megalin is encoded by the gene LRP2; this is related with low-density lipoprotein gene family receptor $[1,2]$.

The expression and variation in the gene LRP2 has been studied, and can explain the development of different Mendelian diseases such as Donnai-Barrow syndrome, Lowe syndrome, Stickler syndrome, Dent's disease or complex traits with thresholds, such as; prostate cancer, hepatocellular carcinoma, neural tube defects, degenerative osteoarthropathy, obesity, gout, autism spectrum disorders, decreased bone mineral density, dyslipidemia, Alzheimer's disease, gallstones, poor maternal nutrition, proteinuria and diabetic nephropathy.

If the endocytosis of the vitamin B-12 and folate are mediated by megalin which depend on providing therapeutic blood levels of these nutrients, the association studies with LRP2 variants and their mRNA expression levels, are required to correlate with levels of vitamin B-12 and serum folate to determine whether it can be used as predictors in therapy, medical support and metabolic control of these diseases, especially in traits or complex diseases. The SNP candidate from LRP2 gene for the associated studies, previously validated are; rs133980 (associated with hypertension), rs2544390 (associated with gout and alcohol drinking), rs1050700 (associated with glomerular filtration rate) [3-9]. The SNP rs3755166, rs2075252, rs4668123 (associated with central adiposity), rs2075252 and haplotype GA of rs4667591/ rs2075252 (associated with bone mineral density), the rs3755166 (associated with Alzheimer's disease), the mutation p.His498Gln (associated with type 2 diabetes mellitus) and the variant $\mathrm{c}$. $+193826 \mathrm{~T} / \mathrm{C}$ (associated with hypercholesterolemia) [10-12]. It is necessary to establish the genetic profiles of each population in relation to serum circulating levels of folate and vitamin B-12, because each population has its own genetic structure and can vary this phenotype. Also can even be useful for dieticians or family physicians in order to provide a more adequate diet to help maintain better therapeutic serum levels.

Recently, Selenium (Se) and its metabolism has become important, specifically the first level of health care which is used by many doctors for their antioxidant properties as an adjuvant in the treatment of many complex and Mendelian diseases, as in the case of cystic fibrosis, inflammatory bowel disease, cancer, complex traits such as KashinBeck disease $[13,14]$. Selenium plays a role in bone physiology as best reflected by Kashin-Beck disease, an endemic osteoarthritis. In a murine bone model $\mathrm{Se}$ is not associated with the mineral but exclusively with the organic matrix. Genetic ablation of Seppexpression (selenoprotein $\mathrm{p}$-SePP) causes a severe decline in serum with a mild reduction in bones. Of the two known SePP receptors, Lrp8 was detected in bones while Lrp2 was absent. This showed that Lrp8 mRNA concentrations were strongly increased in bones of Seppknockout mice likely in order to counteract the developing Se 
deficiency. This data highlights, SePP as the essential Se transporter to bones, it suggest a novel feedback mechanism for preferential uptake of Se in Se-deprived bones, which contributes to our understanding of the bone phenotype in the inherited selenoprotein biosynthesis mutations [14].

Currently there are many advances in the genetic study of selenium metabolism, particularly the Selenoproteins, this is a distinct class characterized by the co-translational incorporation of selenium $(\mathrm{Se})$ in the form of the 21st amino acid selenocysteine. Selenoproteins provide a defense against oxidative stress. Many selenoproteins are highly expressed in the brain, and the mouse knockout studies have determined that they are required for brain development. Also, the deficits include impairments in cognition and motor function, seizures, hearing loss, and altered thyroid metabolism. Considering defense against oxidative stress also is a role of neurodegenerative disease. Studies in cell culture and rodent models have demonstrated that Se administration attenuates oxidative stress and prevents neurodegeneration. It appears likely that, supplementation Se may only benefit certain subpopulations, such as those that are either deficient or possess genetic variants that affect Se metabolism [15]. For example, it was reported that rs7579 in the selenoprotein P (SEPP1) gene and is rs9880056 in the SELK gene (selenoprotein K) is associated with the risk of advanced (stage III/IV or IV) prostate cancer [16,17]. The SNPs rs28919926 and rs146125471 showed association with an acute insulin response, while rs16872779 was associated with fasting insulin levels in Hispanics families. This suggest a role for SEPP1 in insulin resistance [18]. Finally, it was reported that the rs7901303 in the gene SEPHS1 (Encoding Selenophosphate Synthetase 1, essential component of selenoprotein synthesis) showed association with Se levels and development Crohn's disease [19].

All of these studies show the importance of folate, vitamin b-12 and selenium in the health disease process, as various mutations or polymorphisms in genes related to metabolism, leading to monogenic or complex disorders. Those engaged in nutrigenetics and nutrigenomics require more focus on doing genetic studies, of association, epistasia, gene-gene interaction, gene-environment interaction and expression gen and genotype-phenotype correlation to be able to estimate the epidemiological importance of variations in the serum levels of folate, vitamin b-12 and selenium with the development of the disease. The state governments should provide funds to finance the genetic profiles, because they can be very useful as a preventive medium and long term strategy, and can be used for physician primary care, nutritionists, internists, neurologists, rheumatologists, endocrinologists, nephrologists and cardiologists.

\section{Acknowledgment}

MSc. Evan Wesley Bejarano Welch, native translator, Language Centre of the Universidad de la Sierra Sur, Oaxaca, México, for the technical support.

\section{References}

1. Kur E, Mecklenburg N, Cabrera RM2, Willnow TE, Hammes A (2014) LRP2 mediates folate uptake in the developing neural tube. J Cell Sci 127: 2261-2268.
2. Kozyraki R, Cases O (2013) Vitamin B12 absorption: mammalian physiology and acquired and inherited disorders. Biochimie 95: 1002-1007.

3. Sung YJ, de Las Fuentes L, Schwander KL, Simino J, Rao DC (2014) Gene-Smoking Interactions Identify Several Novel Blood Pressure Loci in the Framingham Heart Study. Am J Hypertens pii: hpu149.

4. Nakayama A, Matsuo H, Shimizu T, Takada Y, Nakamura T, et al. (2014) Common variants of a urate-associated gene LRP2 are not associated with gout susceptibility. Rheumatol Int 34: 473-476.

5. Rasheed H, Phipps-Green A, Topless R, Hollis-Moffatt JE, Hindmarsh $\mathrm{JH}$, et al. (2013) Association of the lipoprotein receptor-related protein 2 gene with gout and non-additive interaction with alcohol consumption. Arthritis Res Ther 15: R177.

6. Parsa A, Fuchsberger C, Köttgen A, O'Seaghdha CM, Pattaro C, et al. (2013) Common variants in Mendelian kidney disease genes and their association with renal function. J Am Soc Nephrol 24: 2105-2117.

7. Beydoun MA, Tanaka T, Beydoun HA, Ding EL, Ferrucci L, et al. (2013) Vitamin D receptor and megalin gene polymorphisms are associated with central adiposity status and changes among US adults. J Nutr Sci 2: e33.

8. Hamajima N, Naito M, Okada R, Kawai S, Yin G, et al. (2012) Significant interaction between LRP2 rs2544390 in intron 1 and alcohol drinking for serum uric acid levels among a Japanese population. Gene 503: 131-136.

9. Wang C, Hu YM, He JW, Gu JM, Zhang H, et al. (2011) Association between low density lipoprotein receptor-related protein 2 gene polymorphisms and bone mineral density variation in Chinese population. PLoS One 6: e28874.

10. Wang LL, Pan XL, Wang Y, Tang HD, Deng YL, et al. (2011) A single nucleotide polymorphism in LRP2 is associated with susceptibility to Alzheimer's disease in the Chinese population. Clin Chim Acta 412: 268-270.

11. Mii A, Nakajima T, Fujita Y, Iino Y, Kamimura K, et al. (2007) Genetic association of low-density lipoprotein receptor-related protein 2 (LRP2) with plasma lipid levels. J Atheroscler Thromb 14: 310-316.

12. Carrillo C, González M, Ramirez-Garcia SA (2009). Detección molecular de una variante de secuencia del gen que codifica para megalina y el desarrollo de insuficiencia renal causada por diabetes mellitus tipo 2 . Bioquimia 34: 59.

13. Ciofu O, Lykkesfeldt J (2014) Antioxidant supplementation for lung disease in cystic fibrosis. Cochrane Database Syst Rev 8: CD007020.

14. Pietschmann N, Rijntjes E, Hoeg A, Stoedter M, Schweizer U, et al. (2014) Selenoprotein P is the essential selenium transporter for bones. Metallomics 6: 1043-1049.

15. Pitts MW, Byrns CN, Ogawa-Wong AN, Kremer P, Berry MJ (2014) Selenoproteins in nervous system development and function. Biol Trace Elem Res 161: 231-245.

16. Geybels MS, van den Brandt PA, Schouten LJ, van Schooten FJ, van Breda SG, et al. (2014) Selenoprotein gene variants, toenail selenium levels, and risk for advanced prostate cancer. J Natl Cancer Inst 106: dju003.

17. Méplan C, Rohrmann S, Steinbrecher A, Schomburg L, Jansen E, et al. (2012) Polymorphisms in thioredoxin reductase and selenoprotein $\mathrm{K}$ genes and selenium status modulate risk of prostate cancer. PLoS One 7: e48709.

18. Hellwege JN, Palmer ND, Ziegler JT, Langefeld CD, Lorenzo C, et al. (2014) Genetic variants in selenoprotein P plasma 1 gene (SEPP1) are associated with fasting insulin and first phase insulin response in Hispanics. Gene 534: 33-39.

19. Gentschew L, Bishop KS, Han DY, Morgan AR, Fraser AG, et al. (2012) Selenium, selenoprotein genes and Crohn's disease in a case-control population from Auckland, New Zealand. Nutrients 4: 1247-1259. 